\title{
Human Relationship with Animals Reading the Book of Tobit in the Light of Christian Tradition
}

\section{Gianfranco Nicora $^{1}$ - Alma Massaro ${ }^{2}$}

${ }^{1}$ Independent Scholar

${ }^{2}$ PbD Candidate in Philosophy at University of Genoa, Italy

doi: 10.7358/rela-2013-002-mass

almamassaro@gmail.com

gianfranco.nicora@libero.it

\begin{abstract}
In this paper we argue that the Book of Tobit, by presenting a new model of companionship between a buman being and a dog, constitutes a vision of a future era, where humans and animals will live as fellows rather than rivals. In so doing we focus on the reading of the Holy Scriptures placing emphasis on the role of animals, moving from the Book of Tobit through the book of Genesis, to Jesus' new alliance and the promise of new heavens and a new earth. We also show that the Book of Tobit, even if it is deeply encouched in the anthropocentric view particular to Jewish culture, includes insights of non-violence toward animals as well as vegetarianism that are both fundamental and prophetic aspects of the new ethic suggested by Isaiah's prophecies and by the good news announced in the New Testament.
\end{abstract}

Keywords: Animal theology, Scripture, book of nature, Christocentrism, theocentrism, anthropocentrism, eco-theology, covenant, ethics of respect, animal ethics.

\section{INTRODUCTION}

According to theology, God manifests herself/himself in Nature and Scripture. Hence theological research turns both to Nature - investigated by means of the various kinds of human knowledge - and to the Scripture which has been transmitted by Christian tradition. The rational analysis of Nature is an important principle for Christianity and it is notable how common it is, in ethical matters, to resort to the so-called 'natural law': i.e. the traditional ethics which condemns some behaviour to be 'against life'. 
This principle has to undergo a careful critical consideration, because the use of this criterion has sometimes occurred with a high form of absolutism, as if natural laws consisted of an exact handbook of specific and immutable rules, deductible from Nature itself. It is instead a complex criterion, which takes into account the whole reality of Creation in the variety and complementarity of its structural elements, and, above all, it is a dynamic criterion, as much as the reality of Creation is evolutionary and dynamic. This means that Nature is not a complete and finite reality (entelecheia) but is subject to fundamental development and evolutionary processes. It does not mean simply that evolution concerns only human knowledge of Nature and Universe, but the deeper meaning is that Nature itself evolves according to a process of loss and recovery of data - data that is (from time to time) gathered, distinguished, and put forward by knowledge and science.

Is it possible to attribute some permanent meanings to Nature within these dynamic processes? Undoubtedly it is - and this is also what theological thought is trying to do - but not by thinking about a 'natural order' perceived and defended as immutable, but rather by moving from human's self-understanding of Nature bic et nunc and comparing it, as far as possible, with the knowledge of other times and places. This is the only way we can refer to Nature and its laws; we have to maintain a critical reliance on the culture in which, bic et nunc, we are immersed, by means of, for example, the results of biological disciplines (sociobiology, physiology, comparative anatomy, neuroscience, ethology).

Even referring to the Word of God, stated in the Old Testament, is not an immutable criterion. Without a doubt the Christian idea of mankind is that of human beings as the creatures called to adhere freely to God's project, through the basic exercise of their freedom, resolute in their destiny. This supreme saving act is the act of faith, which lets the human being liberally abandon her/himself to God. And, as we will try to demonstrate in the following pages, since God is love, to liberally adhere to God and to her/his project means to choose a life inspired not by the ethics of dominion but by the ethics of love. According to the New Testament, the human being is the creature called to choose a life of love; this is his greatest responsibility and his high moral dignity before the entirety of living beings, human and nonhuman (Jn 15:9-10 RSV). Every ethical choice, both in its intentional birth and in its concrete act, is called to be a mediation of love.

In the Bible the laws about human behavior are frequent and precise, it seems as if we have nothing more to do than accept them and pass them as firm laws to those who wish to listen to the teachings of Christian faith. In reality, the problem is more complex. If the human condition - as explained above - certainly follows from the Revelation (that is the most 
concise word about humankind that God conveyed to us) it is not the same for the various norms proposed in the Ancient Testament: do they represent a lasting word of God, or rather, are they just a human view borrowed from the cultural debate of the time and thus adaptable? This last choice is not an unusual interpretation. Rather it has been proposed and developed by Biblical hermeneutic regarding the entire revealed word. It is even more important for its ethical aspects, with regard to which the Bible seems more influenced by social and cultural issues than in other respects.

But there is, however, a second hermeneutical issue of fundamental relevance, that is the comparison between the Bible and those cultures with which the Bible is in contact and from which it often takes its origins. It is only on this basis that a deconditioning will be possible. Therefore, every theological research has to consider scientific data in order to reach a correct understanding of the Bible and of the data of the 'decoded' faith, in order to have a meaningful reflection. For this reason in order to achieve a correct animal and Creation theology it is important to make full use of the 'culture' in which we are immersed - in all its elements and positive contributions - and of our environment. And, as Valsecchi suggests:

When we speak about 'culture', we do not identify it with the real habits of a certain time or of a certain environment, nor do we identify it with a specific ideology. Looking at the contemporary socio-anthropological ideas, we consider 'culture' to be the dynamic effort, that is never complete, to organize the elements of human co-existence around human fundamental needs as discovered and prioritized by each group. (Valsecchi 1973, 26-30) ${ }^{1}$

In the light of these considerations it is possible to start a re-reading of Holy Scriptures paying attention to the role of animals, moving from the Book of Tobit passing through the book of Genesis until Jesus' new alliance and promise. It will be clear that the Book of Tobit could be considered a vision of the future era of the peaceable kingdom - by presenting a new model of companionship between a man and a dog to the reader - even if it is deeply encouched in the anthropocentric view particular to Jewish culture - which defies an understanding of the absolute non-violence toward animals as well as vegetarianism which are both fundamental and prophetic aspects of a new ethic among sentient beings.

1 Translation is our. 


\section{The BoOK OF Tobit}

The Book of Tobit is a huge fresco in which the journey represents life. It is not about history, in fact it is a popular happy-ending tale with a sapientialdidactic goal. The biblical image of Tobias who leaves for a long journey with an angel and his dog - "So they both went out and departed, and the young man's dog was with them" (Tb 5:16) - is the parable of our journey on Earth, during which animals and angels are our companions. The style is fictional, as it is full of twists, and of supernatural incursions in daily life, which leave the reader waiting the happy ending with bated breath.

The central part of the book is about a blind man called Tobiel, and his son, Tobias, who is sent by his father to collect some money owed to them by a relative. Tobias departs, accompanied by his dog and Azariah, who offers to protect him during the journey. The young man does not realize that Azariah is an angel, disguised as a wayfarer, even if from the very beginning Azariah shows a superhuman knowledge, suggesting Tobias to keep the gall, the heart and the liver of a fish he had caught in the Tigris. Furthermore Azariah tells Tobias about the sad story of his cousin, Sarah, who has been condemned by a demon, Asmodeus, to be always widowed but he also reveals to him how to defeat the demon by burning the fish's heart and liver. For this reason when Tobias falls in love with Sarah and gets married to her, he already knows how to defeat the demon. In the final part of the journey Tobias, Sarah, Azariah, and the dog go back to Nineveh where Tobias's father is healed from blindness as soon as the son puts the gall of the fish on his eyes. At this point the father would like to reward Azariah, who instead reveals his angelic nature ascending to the Heavens leaving the protagonists astonished.

In addition to all the traditional characters of the story, there are others which are nonhuman living beings:

- The domesticated dog, who is with Tobias at the beginning and at the end of his journey (Tb 5:16, 11:4). During the VI century B.C. the dog was regarded as an unclean being but here, for the first time in the Ancient Testament, a dog is presented as a friend and companion, together with the angel and in opposition to the demon Asmodeus.

- The fish provides the key elements to solve Tobia's problems: with its heart and liver he will drive away the devil and with its gall his father will be healed from blindness ( $\mathrm{Tb}$ 6:1-4).

- The sparrows, accused of having provoked Tobiel's blindness: "I slept by the wall of the courtyard, and my face was uncovered. I did not know that there were sparrows on the wall and their fresh droppings fell into my open eyes and white films formed on my eyes" (Tb 2:9-10). 
- The young goat who enters Tobia's home bleating and represents an element of wealth in Tobit's family (Tb 2:12-13).

- The angel: his name, Raphael, means 'God who healed'. Raphael - who behaved as a personal entity with its own will and not as an Jhwh's alter ego.

- The devil: in Tobit 3:8 is one of the few demons who is called by its own name, Asmodeus. Its name comes from Persian Aeshma Deva, which means 'he who kills' - in antithesis to Raphael, which means 'God who healed'.

In this sacred history all the characters, human and nonhuman, remind us about the well-known book of Genesis, where the fresco becomes cosmic and the journey starts from the depth of the millennia, when the whole of Creation (sky, earth, water, fire, sun, moon, plants, animals, humans, angels) was born from the breath of the Holy Spirit.

\section{THE COSMIC JOURNEY: THE THEOCENTRIC VISION}

The first account of creation (Gn 1:1 - 2:4) is the first text about ecotheology. The main part of the story regards God as an architect who creates the place, the rooms and then settles the inhabitants who all live under the same roof on different floors. The text is poetic and its literary genre is didactic; in a polytheistic cultural context it teaches that:

- The universe is the work of God.

- Every creature (even the green grass) comes from Her/His Goodness and Beauty.

- Every creature is an image of God, who is reflected in it (Gn 1:31 "And God saw everything [...] was very good"; in Hebrew tov means both good and beauty).

- Humankind (male and female) (in the Hebrew text: is, otò), created as an image of God, has to take care of Creation, in the same way as God acts towards all Her/His creatures. The meaning of the verb kavash is not 'subdue', but rather 'take care of the Earth' in a loving and harmonious relationship. Regarding the verb usually translated as 'dominate', radah, it suggests to rule, to lead, to pasture, as the action of the shepherd who loves his herd (De Benedetti 1999, 16-20).

In this text the vision is theocentric, since the whole Creation reflects God's beauty and goodness and the relationship between the human race and animals is based on a strong sense of kinship (De Benedetti 1999, 29-30). 
In the second account (Gn 2:4-25) God is represented as a potter. The Creator moulds a body out of mud and makes it come alive by blowing Her/His vital breath on it. Human beings - and then animals - come from the earth and are given life by God's spirit: "When thou sendest forth thy Spirit, they are created" (Ps 104:30). The story continues with three pictures, where the only changes are the appearance or the disappearance of a character.

First picture. God says: "It is not good that the man should be alone; I will make him a helper fit for him" (Gn 2:18) literally 'one who is in front'

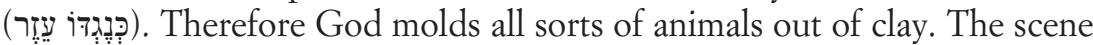
is suggestive, everything seems perfect, but God starts to think about an empty part of Her/His Creation. The man, that is "the earthly" (הָאזדָם baadam, "Adam'), who was put "in the garden of Eden" by God (2:15) would not be happy if he remained alone, because the male is an incomplete human being.

Second picture. God tells Adam to name all the animals: "[...] and whatever the man called every living creature, that was its name. The man gave names to all cattle, and to the birds of the air, and to every beast of the field" (Gn 2:19-20). In biblical language 'to name' means to recognize one's paternity over the one who receives the name, as it happens in Matthew 1:18-21 when Joseph is told by the angel to give the name to Jesus, who will be therefore considered Joseph's child. However for man there was not anyone like 'one who is in front'.

Third picture. God gives Adam a female companion taken from Adam's middle (Gn 2:21-22). "This at last is bone of my bones and flesh of my flesh" (2:23). He calls her "she-man" (xwe, ishà; feminine of $y s h$, "man') because she was taken from the man (2:23). Now the human being is not simply an "earthly" (אישד (ysh), 'madàm): now he ind she is X (ishà), 'woman'.

This story too is an example of the didactic genre and in a male chauvinist cultural context - where woman is subordinate to man and considered almost the same as the wheat flour she kneads, as the millstone which crushes the grain of wheat, as the donkey - it teaches us that:

- Male and female complete each other and have the same dignity.

- The same breath of life is given to both humans and other creatures.

We find here the same kinship of the first account. The relationship between the human race and other animals is based on the father-child one, as God is human's father so other living beings are human's brothers, indeed human's children, as the young sheep of the second book of Samuel who grew up in the poor house "it used to eat of his morsel, and drink from his cup, and lie in his bosom, and it was like a daughter to him" 
(2 Sm 12:3). We can say that an interspecific and universal fellowship does exist. But it is at this stage of the story and of the journey that Adam and Eve meet the cunning snake on their path.

\subsection{The snake and the flood}

In the third chapter of Genesis, we find the snake instilling doubt in the human mind, by provoking Eve to question God's goodness and sincerity ${ }^{2}$. And it is in this temporary losing of faith that human beings also lose innocence and, therefore, commit sin (Gn 3:1-5). By simplifying the intricate matter about the meaning of the snake, tradition believes that the snake is Satan, the demon. Inside the snake - an animal like any other - a special energy is at work. Like in the Book of Tobit, Raphael appears in disguise and the demon pretends to be Asmodeus, so in Genesis, Satan - a liar since the beginning - hides itself in the snake and takes advantage of Eve and Adam's freedom. The Bible shows the snake as a cunning enemy, the cause of humans' loss of initial innocence - the innocence which enabled them to have a direct and pure relationship with God and, hence, with the whole creation. By sinning, humans cause the fall of other living beings. Animals do not sin, but they are unconsciously involved in humans' sin.

The LORD God said to the serpent, "Because you have done this, cursed are you among all cattle and above all wild animals"; [...] To the woman he said, "I will greatly multiply your pangs in childbearing; in pain you shall bring forth children, yet your desire shall be for your husband, and he shall rule over you". And to the man he said, "[...] cursed is the ground because of you; in toil you shall eat of it all the days of your life; thorns and thistles it shall bring forth for you; and you shall eat the plants of the field. In the sweat of your face you shall eat bread til you return to the ground, for out of it you were taken; you are dust, and to dust you shall return". (Gn 3:14, 16-20)

But it is with the flood that the relationship between living beings was completely modified. Once again the whole community of life is involved in God's punishment of human sin. Human unfaithfulness causes the first environmental disaster. Once again, the harshness of the human heart is what causes harmony to deteriorate. For this reason in the sixth chapter of the Book of Genesis all living beings are killed among with human beings, except those in the care of Noah, the only man who has found favour in

2 Interestingly, they are not surprised at snake's words, because at the beginning interspecies communication was an ordinary event: even God descends to the Garden in order to talk and walk with human beings. 
God's eyes. And once the water receded, God established his covenant with Noah and all living beings with him:

Then God said to Noah and to his sons with him, "Behold, I establish my covenant with you and your descendants after you, and with every living creature that is with you, the birds, the cattle, and every beast of the earth with you, as many as came out of the ark [...]". And God said, "This is the sign of the covenant which I make between me and you and every living creature that is with you, for all future generations: I have set my bow in the clouds, and it shall be a sign of the covenant between me and the earth [...]. When the bow is in the clouds, I will look upon it and remember the everlasting covenant between God and every living creature of all flesh that is on the earth". (Gn 9:8-10, 12-13,16)

\subsection{Noab and the new covenant in the sign of rainbow: anthropocentrism}

Once again with the flood, the whole of creation is involved in the punishment of human guilt. God makes an 'everlasting covenant' with every living creature on the Earth, hence the animal and vegetable kingdoms are included. After the flood a new Earth is born, a new place inhabited by the people of the Ark, a new hope is rekindled but, at the very same time, a new deterioration of the relationship among living beings occurs: humans are now allowed to eat other animals and they, in turn, will fear humans. Nevertheless, God, in order to remind humans that life does not belong to them, forbids them to eat the animals' blood (Gn 9:4). Blood, in fact, contains life and life belongs only to God. However, very soon the human beings, because of their sinful nature, will consider themselves the owners of the whole of Creation, forgetting the alliance with God and, hence, their solidarity with animals. The theocentric vision is now replaced by an anthropocentric one and the fellowship model by the domination one. From this moment the split among those who lived together on the Ark starts (Gn 9:3), hence animals are subject to humans' wickedness and dictatorship. Animals, which did not claim to be like God as other creatures did - some angels and human beings - started a path of suffering, which is yet to end.

The Jewish did not forget, however, that these innocent living beings are so similar to them that they could be used in sacrifices. The use of animals in sacrifices is an ancient form of worship linked to the culture of the times, which shows the value of the animals offered to God, which is as important as human life. From that it is possible to understand a little bit further the prohibition to eat animals' blood because blood is the life of every living being, humans' kin. 
Notwithstanding human sinful nature and its predisposition to cruelty, in the Bible and in rabbinic tradition compassion comes gradually to be considered the first criterion that has to guide human behavior towards animals. There are many laws trying to limit suffering among animals: animals have the right to Sabbath (Dt 5:12-14); it is not possible to plough with an ox and an donkey together, in order to avoid the suffering caused by their unequal strength (Dt 22:10); it is forbidden to muzzle an ox when it is treading out the grain because everyone has the right to feed on the product of its own work (Dt 25:4). Thanks to a set of ethical precepts, primeval Jewish anthropocentrism gradually became more moderate.

\section{CHRIST BRINGS BACK HARMONY TO THE CREATION: CHRISTOCENTRISM}

As Isaiah prophetically says, the Heavens and the Earth will generate the Saviour. "Shower, O heavens, from above, and let the skies rain down righteousness; let the earth open, that salvation may sprout forth" (Is 45:8). At a certain point of planet history Jesus - God's heavenly son - appeared on the earth. At the moment of Jesus' birth, born in a manger, we find human and other-than human subjects - as also happens in the Book of Tobit; there was the brightness of the stars, the harmonies of angels, the shepherds, the sheep, the ox and the donkey because they are all included in the process of salvation. During his journey on this earth Jesus teaches care and compassion to the whole of creation, as is well summed up in his own sacrifice, and he abolishes every sacrificial rite, by replacing it with bread and wine, products of the earth and work of human hands - the food of a heavenly kingdom banquet.

As Paolo De Benedetti notes, Jesus' Resurrection is at the basis of a new ethic towards living beings and even towards vegetables.

Even more importantly, if everything that had existence from God and lost it with death does not get it back again, we should conclude that death is more powerful than God, since it triumphs over existence. This was a serious danger for God, who chose his own death in order to announce Resurrection. If a pebble - and not just a blade of grass - did not retrieve its existence, Paul's question "Where, $\mathrm{O}$ death, is your victory?" would be false. (De Benedetti 2009, 36-7) ${ }^{3}$

3 Translation is our. 
And this is because, as Paul says, after Christ's Resurrection the rebirth of the whole of Creation is in gestation:

For the creation waits with eager longing for the revealing of the sons of God; for the creation was subjected to futility, not of its own will but by the will of him who subjected it in hope; because the creation itself will be set free from its bondage to decay and obtain the glorious liberty of the glory of the children of God. We know that the whole creation has been groaning in travail together until now. (Rom 8:19-22)

It means that Creation, without being sinful, has been dragged along to a state of vanity and corruption by humans, from this suffering follows. However this state is not definite, in Christ the whole of Creation finds its hope. This is Paul's Christocentric vision of the whole of Creation. In Paul's theological vision the whole of Creation was made through Christ (Col 1:15-17). Paul's prophetic vision gives us the chance to mention the problem of the meaning and of the divine project inside Creation. In Paul's vision Christ is at the beginning and end of world history. The themes of the final liberation of Creation and of its participation to the glory of God's sons are confirmed in the 'new heavens' and 'new earth' of the Second Epistle of Peter (3:13) and of the Revelation (21:1). The first important news is that this vision is about the liberation of the subject, and not from the matter - as it was in almost every ancient idea of salvation: Platonism, Gnosticism, Docetism, Manichaeism, Catharcism. And it explains why in the final verse the Apostle states this vision of faith with a bold image: the whole of Creation is compared to a woman suffering and groaning from birth pangs. In the human experience, this pain is always mixed with joy, and it is really different from the silent crying of the world, expressed in Virgil's Aeneid (1.462) sunt lacrimae rerum, there are tears of things.

The mention of the labour of Creation can be found in Paul's passage about the different acts of the Spirit. He finds continuity between Creation's and the believers' groans. This last one is directly related to the Spirit: "And not only the creation, but we ourselves, who have the first fruits of the Spirit, groan inwardly" (Rom 8:23). The Spirit is the mysterious power, the powerful energy which drives Creation to its fulfillment. The Spirit which was hovering at the beginning of Creation - is the same for the stars, the sea, the trees, the gazelles, the human beings, and the angels: "For the fate of the sons of man and the fate of beasts is the same; as one dies, so dies the other. They all have the same breath" (Eccl 3:19). The theologian Vito Mancuso calls energy this unique being which is the Spirit (Mancuso 2007, 55). And, as Simon Weil says, "The Greek word which is translated spirit 
literally means fiery breath, breath mingled with fire, and it represented, in antiquity, the notion which science represents today by the word energy" (Weil 2003, 251).

\section{CONCLUSION}

From the above it follows that in Christ Pantocrator the whole of Creation resurrects, and we will find the signs of this renewal in the interspecific and infraspecific harmony between human beings and animals: "The wolf shall dwell with the lamb [...]. The sucking child shall play over the hole of the asp" (Is 11:6-8). But this cannot be understood until human culture has moved away from the ancient anthropocentric Hebrew consideration of the world.

By presenting a new model of relationship between a human being and an animal, the Book of Tobit represents a vision of this peaceful future kingdom. But it can in no way fully represent this new era since it is still deeply entrenched in the anthropocentric view particular to Jewish culture which does not allow an understanding of the attitude of absolute nonviolence toward animals and vegetarianism which follows from the message of the Gospels. However, the reading of this story in the light of Jesus' revelation offers a glimpse of the kin relationship between humans and animals existed at the beginning of the cosmic story and that will be restored with the future era, with Jesus' second advent.

\section{REFERENCES}

De Benedetti, Paolo. 1999. E l'asina disse... L'uomo e gli animali secondo la sapienza di Israele. Magnano (BI): Qiqajon.

—2009. Il Filo d'erba. Verso una teologia delle creatura a partire da una novella di Pirandello. Brescia: Morcelliana.

Mancuso, Vito. 2007. L'anima e il suo destino. Milano: Raffaello Cortina.

Valsecchi, Ambrogio. 1973. Nuove vie dell'etica sessuale. Brescia: Queriniana.

Weil, Simon. 2003. The Need for Roots. Prelude to a Declaration of Duties towards Mankind. London: Routledge Classics. 